\title{
Under-Five Child Health Service Quality and its Determinants in Goncha Siso Enessie District, Northwest Ethiopia, 2016
}

\author{
Ayalew Shiferaw ${ }^{1 *}$, Molla Gedefaw ${ }^{2}$ and Muluken Teshome ${ }^{3}$ \\ ${ }^{1}$ Department Carter Center, Ethiopia \\ ${ }^{2}$ Department of Public Health, Ethiopia \\ ${ }^{3}$ Department of Health Science, Ethiopia
}

*Corresponding author: Ayalew Shiferaw, The Carter Center Ethiopia, Ethiopia

\begin{abstract}
Background: Quality of health service is measured based on structure, process and outcome elements and has multidimensional concept that has been defined in various ways. It is an important aspect of health service delivery system and must be given priority in most countries.

Methods: A facility based cross sectional quantitative and qualitative study design was employed from January- May 2016 on 396 guardians of under five children. The data were collected using structured exit interviews, facility assessment checklists and record reviews. Data was cleaned and entered Microsoft office Access, EPI info and analyzed by Statistical Package for the Social Science. Binary and multivariate logistic regression was used to identify factors of guardians' satisfaction and odds ratios, $95 \% \mathrm{CI}$ and p-value was computed to measure the presence and strength of associations.

Results: The study showed that health centers and health posts on average fulfilled $32.4 \%$ of the health human power need and $44.1 \%$ of major equipment requirement against the national standards. The average adherence of health professional with guidelines of pneumonia and diarrhea managements was $76 \%$ and $65.6 \%$ respectively. Malnutrition was inappropriately managed and alarming in all components which needs program interventions. The composite average satisfaction level of guardians was $54.3 \%$. Adequacy of information given about child health service (OR=0.49, 95\% CI, $=0.27,0.91)$, expectation about the health services $(\mathrm{OR}=0.46,95 \% \mathrm{CI},=0.23,0.91)$, privacy given during treatments $(\mathrm{OR}=0.21,95 \% \mathrm{CI},=0.08,0.54)$ and preference of health institutions were the predictor variables $(\mathrm{OR}=0.18,95 \% \mathrm{CI}=0.09,0.35)$ for under five child health service satisfactions of guardians.

Conclusion: The overall quality of health service was low compared to studies done at different areas on quality of health care. The health institutions were facing shortages of human power, material resources and low adherence with standard treatment guidelines especially on diarrhea and malnutrition managements. The responsible bodies of health sectors at different levels should take actions to improve institutional capacity and performance of care providers in order to improve quality of health services. There should also be continuous monitoring systems to health facilities focused on health care services to strengthen institutional capacity and performance of care providers.
\end{abstract}

Abbreviations: IMCI: Integrated Management of Childhood Illness; GMP: Growth Monitoring and Promotion; OTP: Out Patient Therapeutic Program; GMP: Growth Monitoring and Promotion; EPI: Expanded Programmed on Immunization

\section{Introduction}

According to Avedis Donabedian, health care service quality is defined as a conceptual and multidimensional framework that should be measured based on structure, process and outcomes
[1]. It is expressed in terms of quality of technical care consists in the application of medical science and technology in a way that maximizes its benefits to health without correspondingly increasing 
its risks [2]. Willy De Geyndt also define that quality of health care as a multidimensional and multifaceted concept interwoven with value judgments about what constitutes good quality and proposed a conceptual model based on three basic elements-structure, process, and outcome [3]. A review of Integrated Management of Childhood Illness (IMCI) implementation in developing countries and elsewhere indicated the positive impact of IMCI on child health, quality of care and referrals of sick children from firstlevel and community care to higher units [4]. The Government of Ethiopia adopted the Integrated Management of Childhood Illness (IMCI) strategy in 1996 as a key strategy to improve quality of child health care at all levels in order to reduce child mortality and improve child health development [5]. It also adopts Integrated Community Case Management (ICCM) for common child hood illness in 2005 to complement facility-based management and used as a strategy to deliver antibiotics outside of health facilities where access to treatment is poor [6,7]. Pneumonia and diarrhea remain major killers of young children that account for $29 \%$ of all deaths of children less than 5 years of age but only $60 \%$ of children with suspected pneumonia access appropriate care; only $31 \%$ of children with suspected pneumonia receive antibiotics and only $35 \%$ of children with diarrhea receive oral rehydration therapy [8].

Most health professionals were experienced and well trained, but they perform $77 \%$ of adequate diagnosis established in consultations and triage and attention to danger signs were poor. An antibiotic was prescribed in almost half of the consultations, but antibiotic use was unwarranted in one-third of these cases. Growth Monitoring and Promotion (GMP) and nutritional counseling were consistently ignored during sick child visits and HIV status was seldom asked about or investigated, for the mother or for the child $[9,10]$. Quality of care provided at a tertiary hospital in SouthEastern Nigeria indicates that the overall satisfaction score of the respondents was $66.8 \%$. Specifically, the respondents expressed satisfaction with patient-provider relationship, patient-provider communication, accessibility, hospital environment, dissatisfaction with hospital bureaucracy and patient waiting time was $81.5 \%$, $79.9 \%, 74.2 \%, 68.2 \%, 48.8 \%$ and $48.3 \%$ respectively [11]. Lack on job-based training, poor performance of health workers, shortage of staffs, shortage of proper equipment at the periphery centers, lack of organization of care in the peripheral facilities and lack of timely referrals were the major determinants for quality of neonatal care in Tanzania [12].

Most of the reported studies had been done in hospitals and the majority has been in industrialized countries. A great deal of this work had focused on the care of patients with specific diagnosis and data had been collected on relatively easy points of diagnosis or therapy and the results of these actions. Even though patient satisfaction is higher in Ethiopia compared to other countries; there are intertwined problems that affect quality of health service at all levels. There is no growing interest to assess quality of integrated under- five child health service at levels of the country as compared to its access. There for, the present study is planned to address the prevailing knowledge gap $[13,14]$. To the best of the knowledge of the researcher, studies addressing the quality of health care rendered to under- five children on diarrhea, pneumonia and malnutrition management are virtually absent. The result of this study was will address the prevailing knowledge gap and had paramount importance for district health managers, practitioners, and researchers. It had also suggested points of difficulties at the service utilization and focused on the weak parts of activities that will contributed to define the conditions for implementing any policies and oriented towards the attainment of "Quality Health for All".

\section{Methods}

This study was a facility based cross-sectional study by using quantitative and qualitative data collection methods that was conducted between January, 2016 to May, 2016 in Goncha Sisso Enessie district, North Eastern Ethiopia. All 7 health centers and 15 randomly selected health posts from 37 health posts were included in the study. Under-five Out Patient Department (OPD), Out Patient Therapeutic Program (OTP) and Growth Monitoring and Promotion (GMP) service stations were selected from each health center and health posts for exit interviews, documentary reviews and checklist-based assessments. Data was collected using exit structured interview questionnaire adopted from review of different literatures [15,16], observation checklists and documentary review of selected diseases and then compared with standards [17-19]. Seven data collectors who completed 10/12 grades and speaks Amharic fluently collected the data under supervision of four senior public health professionals.

The sample size was calculated using a single population proportion formula by taking previous prevalence from the study done on the assessment of quality of health care in Jimma zone, Ethiopia [16] with $95 \%$ confidence interval and a precision of $+5 \%$ plus $10 \%$ non-response rate. Accordingly, 396 guardians and their children were included in the study and allocated proportionally to the health facilities based on the size of patients'/client's flow. The collected data were coded, cleaned and entered by Microsoft Office Access 2007, EPI Info 2002 version 3.5.1 and was analyzed by SPSS version. Patient Satisfaction Rating Questionnaire Score: Responses of patients to the 11 statements of questionnaire were put in a 5-points Likert Scale including; very satisfactory (5 scores), satisfactory (4 scores), neutral (3 scores), dissatisfactory (2 scores) and very dissatisfactory (1 score). Then the mean score was calculated from 11 satisfaction questions to determine cut off point for satisfaction level of this study and was 38 points.

A client who had scores above 38 points from 11 question having 5 Likert-like scale points was labeled as satisfied by the service and client/patient below 38 points was categorized as dissatisfied by health service. Bivariate and multivariate analyses were done using logistic regression analysis. Odds Ratio with 95\% Confidence 
Interval was determined to see the association between the dependent and independent variables. $\mathrm{P}<0.2$ was considered and included to multivariate analysis to get more variables for analysis. Independent variables with p-values less than 0.05 in multivariate analysis were considered as significant association with dependent variable. The study protocol was reviewed and approved by health research Ethics Review Committee of the College of Medicine and Health Sciences from Debre Markos University and GAMBY. Moreover, an informed oral consent was obtained from each study subject and the confidentiality and privacy of participants was maintained during data collection.

\section{Results}

\section{Structure/Input Assessment}

Physical Inputs- Supplies, Drugs and Equipment: Electricity was only available at $3(42.8 \%)$ health centers, but even though the back drop of frequent power cuts in the district, only one health center had a backup generator but enough fuel to power backup generators was not available. Whilst running water was available at $1(14.3 \%)$ health center but all of others were unable to provide safe drinking water and only one health center had colored bins for waste disposal. Functioning refrigerators for Expanded Programmed on Immunization (EPI) vaccines were present at all health centers but found only in $1(6.7 \%)$ of health post. Weighing scales for children and thermometer were available at the outpatient departments of almost all health centers $6(85.7 \%)$ and in just over half of health posts $8(53.3 \%)$. Only $1(14.3 \%)$ health center had all the essential pediatric drug lists whilst not a single health post complied fully with the requirement drug lists. Laboratory support supplies for essential laboratory tests were not present in any of health center and were not conducting laboratory tests according to standard operating procedures except one health center. In general health centers, adult OPD fulfilled 14(60.9\%), maternal and child health OPD $7(58.3 \%)$ and laboratory $3(17.6 \%)$ of the required medical equipment. Health centers and health posts, on average fulfilled $30(44.1 \%)$ of which $24(46.1 \%)$ and $6(35.3 \%)$ of medical equipment for health centers and health posts respectively (Table 1).

Table 1: Availability of major equipment in health facilities, Goncha Siso Enessie District, January-May 2016.

\begin{tabular}{|c|c|c|c|c|c|c|}
\hline \multirow{3}{*}{ Departments } & \multicolumn{4}{|c|}{ Major medical equipment } & \multirow{2}{*}{\multicolumn{2}{|c|}{ Total }} \\
\hline & \multicolumn{2}{|c|}{ Health Center, $\mathrm{N}=7$} & \multicolumn{2}{|c|}{ Health Post, $n=15$} & & \\
\hline & Standard & Available & Standard & Available & Standard & Available \\
\hline OPD & 23 & 14 & 5 & 2 & 28 & $16(57.1 \%)$ \\
\hline $\mathrm{MCH}$ & 12 & 7 & 11 & 6 & 33 & $13(39.4 \%)$ \\
\hline Laboratory & 17 & 3 & 0 & 0 & 17 & $3(17.6 \%)$ \\
\hline Total & 52 & 24 & 17 & 6 & 68 & $30(44.1 \%)$ \\
\hline
\end{tabular}

${ }^{*} \mathrm{n}=$ number of health posts

${ }^{*} \mathrm{~N}=$ Number of health center

Personnel: With regard to health human power, health requirements on average; $11(31.4 \%)$ for health centers and $1(50 \%)$ centers and health posts had fulfilled $12(32.4 \%)$ of the manpower for health posts (Table 2).

Table 2: Availability of health Human power, Goncha Siso Enessie District, Northwest Ethiopia, January-May 2016.

\begin{tabular}{|c|c|c|c|c|c|c|}
\hline \multirow{2}{*}{ Health Professionals required } & \multicolumn{2}{|c|}{ Health Center, $\mathrm{N}=7$} & \multicolumn{2}{|c|}{ Health Post, $n=15$} & \multicolumn{2}{|c|}{ Total } \\
\hline & Standard & Available & Standard & Available & Standard & Available \\
\hline Health Officer & 5 & 1 & 0 & 0 & 5 & $1(20 \%)$ \\
\hline Nurse & 17 & 6 & 0 & 0 & 17 & $6(35.3 \%)$ \\
\hline Environmental health professional & 1 & 0 & 0 & 0 & 1 & 0 \\
\hline Laboratory (all levels) & 4 & 1 & 0 & 0 & 4 & $1(25 \%)$ \\
\hline Pharmacy (all levels) & 3 & 1 & 0 & 0 & 3 & $1(33.3 \%)$ \\
\hline Midwife & 3 & 2 & 0 & 0 & 3 & $2(66.7 \%)$ \\
\hline Ophthalmic nurse & 1 & 0 & 0 & 0 & 1 & 0 \\
\hline Psychiatric nurse & 1 & 0 & 0 & 0 & 1 & 0 \\
\hline Health Extension Workers & 0 & 0 & 2 & 1 & 2 & $1(50 \%)$ \\
\hline Total & 35 & 11 & 2 & 1 & 37 & $12(32.4 \%)$ \\
\hline
\end{tabular}

${ }^{*} \mathrm{n}=$ number of health posts

${ }^{*} \mathrm{~N}=$ Number of health centers

Financial Resource: Six (85.7\%) health centers and 15(100\%) health posts did not have budgets to operate a service properly. Only $1(14.3 \%)$ health center pays full duty hour for the health workers and fulfilled required furniture and provided incentives for best performance staffs during the financial year.

\section{Process Assessment}

Screening, Diagnosis and Treatments Pneumonia: 354 children who diagnosed as pneumonia were treated from January to May, 2016 at health centers and health posts. 167(79.1\%) of under 
five children were correctly assessed and diagnosed pneumonia and $152(61 \%)$ under five children were administered appropriate antibiotics at health centers based on IMCI Guideline. 96 (91.4\%) of under five children were correctly assessed and diagnosed pneumonia and 102(97.1\%) under five children were administered appropriate antibiotics at health posts according to IMCI guideline (Table 3).

Table 3: Assessments of pneumonia diagnosis treatment in health facilities, Goncha Siso Enessie District, January- May, 2016.

\begin{tabular}{|c|c|c|c|}
\hline \multirow[b]{2}{*}{ Indicator } & \multicolumn{3}{|c|}{ Document review results ( $\mathrm{N}(\%) \mathrm{N}=252$} \\
\hline & $\begin{array}{c}\text { Health Center } \\
\quad \mathrm{N} 1=249\end{array}$ & $\begin{array}{l}\text { Health Post } \\
\text { N2 }=105\end{array}$ & $\begin{array}{c}\text { Total } \\
\mathrm{N}=354\end{array}$ \\
\hline Children who were Correctly assessed and diagnosed severity of pneumonia based on IMCI Guideline & $167(67)$ & $96(91.4)$ & $263(74.3)$ \\
\hline Children who were administered appropriate antibiotics for pneumonia based on IMCI Guideline & $152(61)$ & 102(97.1) & $254(71.7)$ \\
\hline Appropriate appointments given for guardians based on IMCI Guideline & 196(78.7) & $94(89.5)$ & $290(81.9)$ \\
\hline Average percentage of adherence with guideline & $68.90 \%$ & $92.70 \%$ & $76 \%$ \\
\hline
\end{tabular}

*N1=Number of documentary assessed children at health center

Screening, Diagnosis and Treatments of Diarrhea: 391 children who had diarrhea were treated from January- May, 2016 at health centers and health posts. 196(77.8\%) of under five children correctly assessed diarrhea and classified their dehydration but only $30(11.9 \%)$ under five children were administered and monitored their rehydration plans appropriate to the severity of dehydration
*N2=Number of documentary assessed children at health post at health centers based on IMCI Guideline. 135(97.1\%) of under five children were correctly assessed diarrhea and classified their dehydration and $108(77.7 \%)$ under five children were administered and monitored their rehydration plans appropriate to the severity of dehydration at health at health posts according to IMCI guideline (Table 4).

Table 4: Assessments of pneumonia diagnosis treatment in health facilities, Goncha Siso Enessie District, January- May 2016.

\begin{tabular}{|c|c|c|c|}
\hline \multirow[b]{2}{*}{ Indicator } & \multicolumn{3}{|c|}{ Document review results $(\mathrm{N}(\%) \mathrm{N}=252$} \\
\hline & $\begin{array}{l}\text { Health Center } \\
\text { N1 }=249\end{array}$ & $\begin{array}{c}\text { Health Post } \\
\text { N2 }=105\end{array}$ & $\begin{array}{c}\text { Total } \\
N=354\end{array}$ \\
\hline Children who were Correctly assessed and diagnosed severity of pneumonia based on IMCI Guideline & $167(67)$ & $96(91.4)$ & $263(74.3)$ \\
\hline Children who were administered appropriate antibiotics for pneumonia based on IMCI Guideline & $152(61)$ & $102(97.1)$ & $254(71.7)$ \\
\hline Appropriate appointments given for guardians based on IMCI Guideline & 196(78.7) & $94(89.5)$ & $290(81.9)$ \\
\hline Average percentage of adherence with guideline & $68.90 \%$ & $92.70 \%$ & $76 \%$ \\
\hline
\end{tabular}

$\mathrm{N}=$ Number of documentary assessed children, $\mathrm{n}^{*}=$ Number of children who needs antibiotics according to the guideline.

Screening, Diagnosis and Treatments of Malnutrition: 45 malnourished Children were admitted and treated by the Outpatient Therapeutic Program (OTP) at health centers and health posts. All get discharged before they achieved the discharge criteria and didn't stay for 8 weeks under the OTP. None of them were followed children based on the OTP guidelines and 10 (22.2\%) children didn't specify their nutritional status on the registration book after discharge. Recovery rate, death rate and defaulter rate are $44.4 \%$, $35.5 \%$ and $36.3 \%$ respectively. Standards and routine medications given only for $5(11.1 \%)$ OTP cases and $3(42.8 \%)$ heath centers and $11(73.3 \%)$ health posts were done screening for malnutrition routinely during heath care and EPI (Table 5).

Table 5: Comparison of the nutritional treatment results with international Standards; Goncha Siso Enessie District, North Eastern Ethiopia, January- May 2016.

\begin{tabular}{|c|c|c|c|c|c|}
\hline \multirow[b]{2}{*}{ Indicator } & \multicolumn{3}{|c|}{ Admission status } & \multicolumn{2}{|c|}{ Sphere Standards } \\
\hline & $\begin{array}{l}\text { Children Without } \\
\text { Medical Problems }\end{array}$ & $\begin{array}{l}\text { Children with } \\
\text { Medical Problems }\end{array}$ & Total & Acceptable & Alarming \\
\hline $\begin{array}{l}\text { Proportion of children who recovered from severe acute } \\
\text { malnutrition after treated in OTP (Recovery rate) }\end{array}$ & $44.1 \%(15)$ & $45 \%(5)$ & $44.4 \%(45)$ & $>75 \%$ & $<50 \%$ \\
\hline $\begin{array}{l}\text { Proportion of severe acute malnourished children who died } \\
\text { while under the OTP intervention (death rate) }\end{array}$ & $11.7 \%(4)$ & $27.2 \%(3)$ & $15.5 \%(7)$ & $<10 \%$ & $>15 \%$ \\
\hline $\begin{array}{l}\text { Proportion of severe acute malnourished children who } \\
\text { defaulted from the OTP (defaulter rate) }\end{array}$ & $35.3 \%(12)$ & $36.3 \%(4)$ & $35.5 \%(16)$ & $<15 \%$ & $>25 \%$ \\
\hline $\begin{array}{l}\text { The average rate of weight gain (gm kg/ child/ day or rate of } \\
\text { weight gain) }\end{array}$ & \multicolumn{3}{|c|}{ No proper weight monitoring on the OTP/TFU chart } & $>=8$ & $<8$ \\
\hline $\begin{array}{l}\text { Number of weeks that the children stay under the OTP (average } \\
\text { length of stay) }\end{array}$ & 7.5 Weeks & 4 Weeks & 5.8 Weeks & $<4$ Weeks & $>6$ Weeks \\
\hline Routine medications given & \multicolumn{5}{|c|}{$11.1 \%(5)$} \\
\hline
\end{tabular}


Presence of EPI, ORT and ARI: Four (57.1\%) health centers and $15(100 \%)$ health posts had regular and outreach Expanded program of Immunization (EPI). 7 (100\%) health centers and 15 $(100 \%)$ of the health posts had given diagnosis and treatments for Oral Rehydration Therapy (ORT). An ORT corner was available at $4(57.1 \%)$ health centers and 7 (46.6\%) health posts but was only functional at $1(14.3 \%)$ health center and $3(20 \%)$ health posts. All health centers and health posts diagnosed and treated Acute Respiratory Tract Infection (ARI) at their sites accordingly.

\section{Outcome Assessment}

Guardians' Satisfaction: ORT corner was available at 4 (57.1\%) health centers and $7(46.6 \%)$ health posts but was only functional at $1(14.3 \%)$ health center and $3(20 \%)$ health posts. All health centers and health posts diagnosed and treated Acute Respiratory Tract Infection (ARI) at their sites accordingly.

I. Socio-demographic characteristics: Exit interview of guardians at outpatient area was carried out to assess their

Table 6: Socio demographic characteristics of respondents, Goncha Siso Enessie district, Northwest Ethiopia, January- May 2016.

\begin{tabular}{|c|c|c|c|c|}
\hline \multirow{2}{*}{ Background characteristics } & \multirow{2}{*}{ Category } & \multicolumn{3}{|c|}{ Frequency of respondents (N (\%)) } \\
\hline & & Health center & Health post & Total \\
\hline \multirow{4}{*}{ Age of guardians (in years) } & $18-29$ & $48(15.8)$ & $19(20.7)$ & $67(16.9)$ \\
\hline & $30-39$ & $184(60.5)$ & $37(40.2)$ & $221(55.8)$ \\
\hline & $40-49$ & $66(21.7)$ & $34(37)$ & $100(25.3)$ \\
\hline & $50+$ & $6(2)$ & $2(2.2)$ & $8(2)$ \\
\hline \multirow{2}{*}{ Sex of guardians } & Male & $58(19.1)$ & $11(12)$ & $69(17.4)$ \\
\hline & Female & $246(80.9)$ & $81(88)$ & $327(82.6)$ \\
\hline \multirow{2}{*}{ Address } & Rural & $216(71.1)$ & $81(88)$ & $297(75)$ \\
\hline & Urban & $88(28.9)$ & $11(11)$ & $99(25)$ \\
\hline \multirow{5}{*}{ Educational Status } & Unable to read and write & $215(70.7)$ & $74(80)$ & $289(73)$ \\
\hline & Able to read and write & $51(16.8)$ & $11(12)$ & $62(15.7)$ \\
\hline & Primary school (1-8) & 11(3.6) & $2(2.2)$ & $13(3.3)$ \\
\hline & Secondary school (9-12) & $9(3)$ & $5(5.4)$ & $14(3.5)$ \\
\hline & College and above & $18(5.9)$ & - & $18(4.5)$ \\
\hline \multirow{3}{*}{ Religion } & Orthodox-Christian & $302(99.3)$ & $85(92.4)$ & $387(97.7)$ \\
\hline & Muslim & $2(0.7)$ & $6(6.5)$ & $8(2)$ \\
\hline & Protestant & - & $1(1.1)$ & $1(0.3)$ \\
\hline \multirow{6}{*}{ Occupation } & Farmer & $212(69.7)$ & $72(78.3)$ & 284(71.7) \\
\hline & House wife & $35(11.5)$ & $17(18.5)$ & $52(13.1)$ \\
\hline & Government employ & $19(6.2)$ & - & $19(4.8)$ \\
\hline & Daily Laborer & $16(5.3)$ & - & $16(4)$ \\
\hline & Merchant & $11(3.6)$ & $3(3.3)$ & $14(3.5)$ \\
\hline & Private employ & $11(3.6)$ & - & $11(2.8)$ \\
\hline \multirow{2}{*}{$\begin{array}{l}\text { Guardians' travel time within pace } \\
\text { of service (one way) }\end{array}$} & Less than 2 hours & $260(85.5)$ & $83(90.2)$ & $343(86.6)$ \\
\hline & 2 hour or more & $44(14.5)$ & $9(9.8)$ & $53(13.4)$ \\
\hline
\end{tabular}

II. Ratings of guardian's satisfaction: Among guardians, the technical competence of health provider examined the child was the aspect where satisfaction was rated highest $279(70.5 \%)$ satisfaction level with the medical service for which the response rate of the study was $100 \%$. A total of 396 guardians of under-five child who came to health center and health post for health service, 249(62.9\%), EPI and GMP service, 64(16.2\%), EPI, 47(11.9\%), GMP, 34(8.6\%) and OTP, 2(5\%) were interviewed. Most of participants, 304(76.8\%) came to health centers but, 92(23.2\%) of the respondents came to health posts. The respondents age ranged from 18 to 78 years old, with mean age of $30( \pm 6.96$ SD). Most, 327 (82.6\%), of the respondents were mothers as primary caregiver and $64.2 \%$ of them used farming as a means of livelihood. Most of them, 248(75.8\%) didn't attend formal education and only $27(8.2 \%)$ had secondary and above level of education. Regarding to religion, 387(97.7\%) of the respondent were Orthodox Christian, $8(2 \%)$ were Muslim and $1(0.3 \%)$ was protestant. The age of children ranged from 1 month to 60 months, with mean age of 18 months $( \pm 1.47 \mathrm{SD})$. The average walking distance of health centers and health posts was reported to be within half an hour and an hour for $784(86.4 \%)$ and $420(46.3 \%)$ of the respondents respectively (Table 6).

Frequency of respondents $(\mathrm{N}(\%))$

and satisfaction was rated lowest (19.7\%) with the examination skills of health provider. Nearly two fifth of the respondents (38.1\%) responded they were not satisfied with the overall health 
services. $22.2 \%$ of the total guardians did not satisfied with levels of health institution related to availability of drugs, materials and equipment (Tables 2 \& 7). Guardians were asked to evaluate the quality of health service using a structured questionnaire covering 11 items in three component of services. They rated their satisfaction status in 5 levels; Very satisfactory, satisfactory, neutral, dissatisfactory and very dissatisfactory which we later categorized as "Very Satisfactory and Satisfactory" into "Satisfied" and "Neutral, Dissatisfactory and Very Dissatisfactory" into "Dissatisfied" to dichotomize the responses. The mean value of satisfaction based on 5 points of Likert-like scale was 38 points in 11 selected satisfaction questions with minimum value of 16 and maximum value of 53.

Table 7: Level of satisfaction of respondents with the different components of health services, Goncha Siso Enessie district, Northwest Ethiopia, January- May $2016(\mathrm{n}=396)$.

\begin{tabular}{|c|c|c|c|c|c|}
\hline Characteristics & $\begin{array}{c}\text { Very } \\
\text { Satisfactory (\%) }\end{array}$ & $\begin{array}{l}\text { Satisfactory } \\
\quad(\%)\end{array}$ & $\begin{array}{l}\text { Neutral } \\
(\%)\end{array}$ & $\begin{array}{l}\text { Dissatisfactory } \\
(\%)\end{array}$ & $\begin{array}{c}\text { Very } \\
\text { Dissatisfactory (\%) }\end{array}$ \\
\hline Consultation time with health provider & 17.4 & 66.4 & 1 & 6.8 & 8.3 \\
\hline Overall waiting time spent for health service & 12.6 & 65.4 & 2 & 11.4 & 8.6 \\
\hline Examination skills of health provider & 7.8 & 19.7 & 34.6 & 28.8 & 9.1 \\
\hline Overall services & 8.1 & 20.5 & 38.1 & 24.2 & 9.1 \\
\hline Information provided by health provider & 8.6 & 50.5 & 5.6 & 23.5 & 11.9 \\
\hline Courtesy and respect by health provider & 18.2 & 68.2 & 0.5 & 8.1 & 5.1 \\
\hline Technical competence of health provider & 7.6 & 70.5 & 10.9 & 6.6 & 4.5 \\
\hline Availability of instruments during physical examination & 4 & 50.3 & 13.6 & 21 & 11.1 \\
\hline $\begin{array}{l}\text { Level of health institution related to drugs, materials and } \\
\text { equipment }\end{array}$ & 1 & 56.3 & 10.1 & 22.2 & 10.4 \\
\hline Cleanness of health institution & 10.4 & 35.1 & 3 & 40.9 & 10.6 \\
\hline Timely referral system to higher institution & 10.6 & 58.1 & 18.4 & 8.3 & 4.5 \\
\hline
\end{tabular}

Table 8: Satisfaction rate of respondents, Goncha Siso Enessie district, Northwest Ethiopia, January- May 2016.

\begin{tabular}{|c|c|c|c|c|}
\hline \multirow{2}{*}{ Characteristics within place of service } & \multirow{2}{*}{ Satisfaction Level } & \multicolumn{3}{|c|}{ Response rate of guardians (N (\%)) } \\
\hline & & Health Center & Health Post & Total \\
\hline \multirow{2}{*}{ Consultation time with health provider } & Satisfied & $245(80.6)$ & $87(94.6)$ & $332(83.8)$ \\
\hline & Dissatisfied & $59(19.4)$ & $5(5.4)$ & $64(16.2)$ \\
\hline \multirow{2}{*}{ Overall waiting time spent for health service } & Satisfied & $229(75.3)$ & $80(87)$ & $309(78)$ \\
\hline & Dissatisfied & $75(24.7)$ & $12(13)$ & $87(22)$ \\
\hline \multirow{2}{*}{ Examination skills of health provider } & Satisfied & $69(22.7)$ & $40(43.5)$ & $109(27.5)$ \\
\hline & Dissatisfied & $235(77.3)$ & $52(56.5)$ & $287(72.5)$ \\
\hline \multirow{2}{*}{ Overall services } & Satisfied & $64(21.1)$ & $49(53.3)$ & $113(28.5)$ \\
\hline & Dissatisfied & $240(78.9)$ & $43(46.7)$ & 283(71.5) \\
\hline \multirow{2}{*}{ Information provided by health provider } & Satisfied & $149(49)$ & $85(92.4)$ & $234(59.1)$ \\
\hline & Dissatisfied & $155(51)$ & $7(7.6)$ & $162(40.9)$ \\
\hline \multirow{2}{*}{ Courtesy and respect by health provider } & Satisfied & $256(84.2)$ & $86(93.5)$ & $342(86.4)$ \\
\hline & Dissatisfied & $48(15.8)$ & $6(6.5)$ & $54(13.6)$ \\
\hline \multirow{2}{*}{ Technical competence of health provider } & Satisfied & $323(76.3)$ & $77(83.7)$ & $309(78)$ \\
\hline & Dissatisfied & $72(23.7)$ & $15(16.3)$ & $87(22)$ \\
\hline \multirow{2}{*}{ Availability of instruments during physical examination } & Satisfied & $159(52.3)$ & $56(60.9)$ & 215(54.3) \\
\hline & Dissatisfied & $145(47.7)$ & $36(39.1)$ & 181(45.7) \\
\hline \multirow{2}{*}{ Level of health institution related to drugs, materials and equipment } & Satisfied & $171(56.2)$ & $56(60.9)$ & $227(57.3)$ \\
\hline & Dissatisfied & $133(43.8)$ & $36(39.1)$ & $169(42.7)$ \\
\hline \multirow{2}{*}{ Cleanness of health institution } & Satisfied & $130(42.8)$ & $50(54.3)$ & $180(45.5)$ \\
\hline & Dissatisfied & $174(57.2)$ & $42(45.7)$ & $216(54.5)$ \\
\hline \multirow{2}{*}{ Timely referral system to higher institution } & Satisfied & 201(69.1) & $71(77.2)$ & $272(68.7)$ \\
\hline & Dissatisfied & 103(33.9) & $21(22.8)$ & $124(31.3)$ \\
\hline \multirow{2}{*}{ Overall satisfaction } & Satisfied & $148(48.7)$ & $67(72.8)$ & $215(54.3)$ \\
\hline & Dissatisfied & $156(51.3)$ & $25(27.2)$ & 181(45.7) \\
\hline
\end{tabular}


According to guardians' assessment, the overall health service given for children, physical examination skills of health provider, cleanness of health institution, information provided by health provider found to be low with "Dissatisfaction" response rate of $64(21.1 \%), 69(22.7 \%)$ and $130(42.8 \%)$ at health centers but health posts have relatively high response rate of "satisfaction" except physical examination skills of health provider that were "dissatisfied" rate of 40 (43.3\%) respondents. On the other hand, courtesy and respect by health provider, consultation time with health provider, overall waiting time spent for health services and timely referral system to higher institutions was rated better in the health center level setting with "Satisfied" response rates of 256(84.2\%), 245(80.6\%), 223(76.3\%), 229(75.3\%) and $201(69.1 \%)$ respectively. Likewise, in the health post level, "satisfied" response rate for consultation time with health services, courtesy and respect by health extension workers, information provided by health extension workers, overall waiting time spent for health services, technical competence and timely referral system to higher institutions were 87(94.6\%), 86(93.5\%), 85(92.4\%), $80(87 \%), 77(83.7 \%)$ and $71(77.2 \%)$ respectively. Generally, 215(54.3\%) respondents were satisfied with overall services given in the health institutions (Table 8).

Table 9: Predictors of guardians' satisfaction with service at health centres in Goncha Siso Enessie district by selected socio demographic characteristics, Northwest Ethiopia, January- May 2016.

\begin{tabular}{|c|c|c|c|c|}
\hline \multirow{2}{*}{ Explanatory Variables } & \multicolumn{2}{|c|}{ Satisfaction level } & \multirow{2}{*}{ Crude OR(CI) } & \multirow{2}{*}{ Adjusted OR (95\% CI) } \\
\hline & Satisfied & Dissatisfied & & \\
\hline \multicolumn{5}{|c|}{ Educational status } \\
\hline Unable to read and write & 150 & 139 & 1 & 1 \\
\hline College and above & 15 & 3 & $4.63(1.31,16.35) *$ & $8.50(1.59,45.61) *$ \\
\hline \multicolumn{5}{|c|}{ Well informed about the service } \\
\hline Yes & 178 & 95 & 1 & 1 \\
\hline No & 37 & 86 & $0.23(0.15,0.36)^{*}$ & $0.49(0.27,0.91) *$ \\
\hline \multicolumn{5}{|c|}{ Do you prefer this health institution } \\
\hline Yes & 186 & 90 & 1 & 1 \\
\hline No & 29 & 91 & $0.15(0.09,0.25) *$ & $0.18(0.09,0.35) *$ \\
\hline \multicolumn{5}{|c|}{ Did the child get the expected service } \\
\hline Yes & 191 & 95 & 1 & 1 \\
\hline No & 24 & 86 & $0.14(0.08,0.23) *$ & $0.46(0.23,0.91)^{*}$ \\
\hline \multicolumn{5}{|c|}{ Provider keep child's privacy } \\
\hline Yes & 207 & 126 & 1 & 1 \\
\hline No & 8 & 55 & $0.09(0.04,0.19)^{*}$ & $0.21(0.08,0.54) *$ \\
\hline \multicolumn{5}{|c|}{ Provider informed the child's illness } \\
\hline Yes & 132 & 40 & 1 & 1 \\
\hline No & 83 & 141 & $0.18(0.11,0.28)^{*}$ & $0.26(0.14,0.49) *$ \\
\hline
\end{tabular}

*=Significant result

Citation: Ayalew S, Molla G, Muluken T. Under-Five Child Health Service Quality and its Determinants in Goncha Siso Enessie District,

Northwest Ethiopia, 2016. Sur Cas Stud Op Acc J. 1(5)- 2019. SCSOAJ.MS.ID.000122. DOI: 10.32474/SCSOAJ.2019.01.000122. 
Table 10: Suggestions given for service improvement by respondents, Goncha Siso Enessie district, Northwest Ethiopia, JanuaryMay 2016.

\begin{tabular}{|c|c|c|c|}
\hline \multirow{2}{*}{ Suggestion given by respondents } & \multicolumn{3}{|c|}{ Frequency of respondent (N/\%) } \\
\cline { 2 - 4 } & Health Center & Health Post & Total \\
\hline Improve supply of drugs and equipment & $159(52.3)$ & $43(58.7)$ & $213(53.8)$ \\
\hline Treat urban and rural people equally & $77(25.3)$ & $6(6.5)$ & $120(30.3)$ \\
\hline Improve number and mix of care providers & $97(31.9)$ & $7(7.6)$ & $103(26)$ \\
\hline Improve patient handling practice & $88(28.9)$ & $3(3.3)$ & $95(24)$ \\
\hline Supervision of staff performance by responsible body & $56(18.4)$ & 0 & $59(14.9)$ \\
\hline Reduce waiting time & $58(19.1)$ & $1(1.1)$ & $58(14.6)$ \\
\hline Improve management system & $39(12.8)$ & $40(10.1)$ \\
\hline
\end{tabular}

\section{Discussion}

This study assessed the quality of outpatient health service in Goncha Soso Enessie district using structure, process and outcome assessment tools to measure quality health service in seven health centers and fifteen health posts. About $79.1 \%$ of under-five children were correctly assessed and diagnosed pneumonia and $61 \%$ them were administered appropriate antibiotics at health centers based on IMCI Guideline. 91.4\% of under-five children were correctly assessed and diagnosed pneumonia and $97.1 \%$ of them were administered appropriate antibiotics at health posts levels. This result is lower compared to the study done in remote district of Ethiopia by Community case management of childhood pneumonia [6]. 77.8\% of health centers were correctly assessed diarrhea of health and classified their dehydration but only $11.9 \%$ of them were administered and monitored their rehydration plans appropriately to the severity of dehydration at health centers based on IMCI Guideline.

This might be lack of on job training or lack of attention given for severity of dehydrations that needs immediate interventions. 97.1\% of under five children were correctly assessed their diarrhea and classified their dehydrations and $77.7 \%$ them were administered and monitored their rehydration plans appropriately to the severity of dehydration at health posts according to IMCI guideline. This finding similar with the study done at selected district and subdistrict hospitals in Bangladesh [10]. Physical infrastructures of the health institutions were not in good condition with the standards. Most health centers and all health posts were facing shortage of rooms to receive patients at its most possible capacity. Shortage of basic drugs and medical equipment was affecting quality of care in all the study sites. The result showed that the care settings have no enough and mix of professional staffs and was facing deficiency of basic medical equipment that fulfilled only $44.1 \%$ and $32.4 \%$ respectively. $85.7 \%$ of health center and $100 \%$ of health posts did not have enough budgets to fulfill necessary materials and drugs by themselves. This showed lower result compared with the study done on quality of health care at Jima Zone [16] and Health Extension Program Evaluation in Rural Ethiopia [17].
About $57.1 \%$ of health centers and $100 \%$ health posts had regular and outreach Expanded Program of Immunization (EPI). Even though all health institutions had given diagnosis and treatments for dehydration, only $57.1 \%$ of health centers and $46.6 \%$ of health posts had Oral Rehydration (ORT) corner. Among them, there were only $14.3 \%$ functional ORT corner at health centers and $20 \%$ of health posts. This finding is much lower than other study done on health extension program evaluation in Rural Ethiopia [17]. Severe malnutrition was not treated according to standards. All health institution discharged under five patients before they achieved the discharge criteria and didn't stay for 8 weeks. None of them followed children based on the OTP guidelines and $22.2 \%$ of children didn't specify their nutritional status on the registration book after discharge. Recovery rate, death rate and defaulter rate are $44.4 \%, 35.5 \%$ and $36.3 \%$ respectively. This result is far from sphere standard and a study done in low and middle- income couriers and Tigray region $[14,18]$.

About 396 guardians who came to health center and health post for under-five child health service were interviewed for the measurements of satisfaction. $82.6 \%$ of the respondents were mothers as primary caregiver and $64.2 \%$ of them used farming as a means of livelihood, $75.8 \%$ didn't attend formal education but only $8.2 \%$ had secondary and above level of education. The overall satisfaction level (combined average response rate of "Very Satisfactory and Satisfactory" of guardians was 54.3\%. This finding is lower than the study done at South- Eastern Nigeria, Central Ethiopia, Jimma University Specialized hospital and Jima zone [11-16]. The overall satisfaction level in this study decreased as one goes from health post to health center. This might be related lack of training for health professionals and negligence at health centers due to overburden in different tasks since the number and mix of health professionals were found below the standards. In this study, we found that participants had the mean waiting time of $33.5( \pm 23.6 \mathrm{SD})$ minutes for getting the required services. The mean waiting time for getting treatment card and time to see health professional were 11.7 minutes and 14.6 respectively. 
This is lower waiting time compared with the reported study done at Johannesburg, Jimma University Specialized Hospital and Jima zone $[10,16,19]$. Guardians were satisfied with courtesy and respect given by health provider, consultation time with health provider; overall waiting time spent for health service, technical competence of health provider, and timely referrals of children to higher institution with overall satisfaction levels of $54.3 \%$. But this finding is lower than other studies $[9,11,13,15,16,19]$. Analysis of overall satisfaction by socio demographic characteristics showed that educational status was associated with satisfaction, where respondents who were college and above group were more satisfied as compared to those who had lower educational level. This is disagreement with the study in Jimma Specialized Hospital in which satisfaction score was an in inverse relation to educational status. Guardians were dissatisfied with examination skills of health providers and cleanness of health institutions. This finding of this study was similar with finding from Eastern Ethiopia [16, 19].

\section{Conclusion}

Although higher proportion of guardians were satisfied with health service given in the institutions, the courtesy and respect given to respondents by care providers was rated "poor" especially in the health centers. In addition, the patients' privacy keeping practice of care providers was poor at all levels. The strength of this study was that it involves different approaches of data collection such as exit interview, record review and checklists based on the Donabedian framework of health care quality. This study did not address observation methods of data collection during treatments of children at health institutions. The study includes only government health facilities in Goncha Siso Enessie district, so it may not represent all health facilities in the district and in Ethiopia in general. It was recommended that the management of respective health care institutions should take actions for improving institutional capacity and performance of care providers in order to improve quality of care in the study area.

District health office, health centers and health posts should work hard to solve problems related to shortage of drugs and supplies and look for different mechanisms to keep adequate stock of essential drugs and supplies. All concerned body is better to focus on fulfilling human resources, standard medical equipment, establish triage system to give priority for seriously sick child and avoid long waiting time. Training should be given on managements of child hood illness using IMCI guidelines. Concerned bodies should give special emphasis on the management of malnutrition that needs program interventions. Studies on health service quality should be done on specific diseases to solve specific problems related to the service given.

\section{References}

1. Donabedian A (1997) The quality of care: How can it be assessed? 1988. Archives of Pathology \& Laboratory Medicine. Pro Quest Nursing Journals 121(11): 1145-1150.
2. Donabedian A (1988) The quality of care: How can it be assessed? J Am Med Association 260(12): 1743-1748.

3. Willy DG (1995) Managing the quality of health care in Developing Countries: 1st Ed. The International Bank for Reconstruction and Development. Washington, DC, USA.

4. Ahmed HM, Mitchell M, Hedt B (2010) National implementation of integrated management of childhood illness (IMCI): Policy constraints and strategies. Health Policy 96(2): 128-133.

5. Ministry of Health (2005) Health Profile of IMNCI implementation status, Addis Ababa, Ethiopia.

6. Degefie T, Marsh D, Gebremariam A, Tefera W, Osborn G, et al. (2009) Community case management improves use of treatment for childhood diarrhea, malaria and pneumonia in a remote district of Ethiopia: Community case management of childhood pneumonia. Ethiop J Health Dev 23(2): 122-124.

7. Duke T, Tamburlini G (2003) The Pediatric Quality Care Group: Improving the quality of pediatric care in peripheral hospitals in developing countries. Arch Dis Child 88: 563-565.

8. WHO/UNICEF (2013) Ending Preventable Child Deaths from Pneumonia and Diarrhea by 2025: The Integrated Global Action Plan for the Prevention and Control of Pneumonia and Diarrhea (GAPPD). WHO, Geneva.

9. Birna A (2006) The quality of hospital services in eastern Ethiopia: Patient's perspective. Ethiop J Health Dev 20(3): 199-200.

10. Thandrayen K, SaloojeeH (2010) Quality of care offered to children attending primary health care clinics in Johannesburg, South Africa. Journal of Child Health 4(3): 74-76.

11. Iloh G, Ofoedu JN, Njoku PU (2012) Evaluation of patients' satisfaction with quality of care provided at the National Health Insurance Scheme clinic of a tertiary hospital in South- Eastern Nigeria. Niger J Clin Pract 15(4): 469-474.

12. Nicole L, John G, Mrema, Mbwele (2013) Quality of Neonatal Health Care: Learning from Health Workers' Experiences in Critical Care in Kilimanjaro Region, Northeast Tanzania. Primary Health Care, Open Access 3(2): 2167-2179.

13. Ministry of Health (2011) Better medicines for children: Assessment of quality of care for children in selected hospitals in Ghana.

14. Lenters LM, Wazny K, Webb P, Ahmed T, Bhutta ZA (2013) Treatment of severe and moderate acute malnutrition in low and middle-income settings: A systematic review, meta-analysis and Delphi process. BMC public health 13(3): 6-10.

15. Birhanu Z, Assefa T, Woldie M, Morankar S (2010) Determinants of satisfaction with health care provider interactions at health centers in central Ethiopia: A cross sectional study. BMC Health Services Research 10(78): 4-7.

16. Beyene W, Jira C, Sudhakar M (2011) Assessment of quality of health care in Jimma Zone, Southwest Ethiopia: Assessment of Quality of Health Care 21(Supp 1): 49-58.

17. Teklehaimanot HD, Teklehaimanot A (2010) Health Extension Program Evaluation in Rural Ethiopia: HEW and Health Post Performance Survey, Center for National Health Development in Ethiopia. Columbia university 2(2): 11-17.

18. Amare S (2013) The Impact of Ethiopian Health Services Extension Program on Maternal and Child Health Outcomes: The Case of Tigray Region. Public health theses 257: 8.

19. Assefa F, Mosse A, Michael A (2011) “Assessment of Clients” satisfaction with health service deliveries at Jimma University Specialized Hospital. Ethiop J Health Sci 21(2): 104-106. 
(C) (D) This work is licensed under Creative

To Submit Your Article Click Here: Submit Article

DOI: 10.32474/SCSOAJ.2019.01.000122

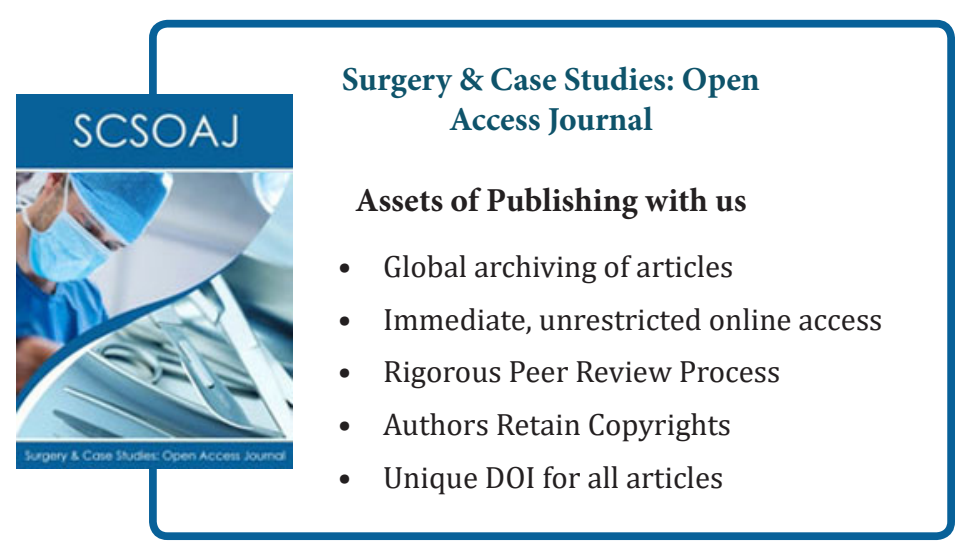

